\title{
Mathematical Model of Soot Blowing Influences in Dynamic Power Plant Modelling
}

\author{
C. Gierow ${ }^{1} \quad$ M. Hübel ${ }^{1} \quad$ J. Nocke ${ }^{1} \quad$ E. Hassel ${ }^{1}$ \\ ${ }^{1}$ Chair of Technical Thermodynamics, University of Rostock, Germany, \\ \{conrad.gierow, moritz. huebel, juergen. nocke, egon. hassel\}@uni-rostock. de
}

\begin{abstract}
Due to the increasing integration of renewable energy sources in the existing power grid the conventional power plants have to set their focus more on flexibility and grid stabilization than supplying the base load. Since this task was not foreseeable when designing the currently existing power plants, they will have to suffer completely different load scenarios than expected. Dynamic modelling of complete steam cycles is a promising way to study the power plant operation of various future scenarios. To adapt the model to real power plant behaviour, especially with a focus on control events, the implementation of effects due to steam blown into the gasside part of the boiler in order to detach soot from the heating surfaces (soot blowing) seem to bring great efforts concerning model validity. Furthermore special control optimizations can be done, for example on spray injection at soot blowing events. In this study temperature measurement data is used in combination with a highly detailed boiler model of a $550 \mathrm{MW}$ hard coal fired power plant to build a mathematical model of soot blowing influence on the different heat exchangers.
\end{abstract}

Keywords: Dynamic Modelling, Power Plant, Soot Blowing, Mathematical Modelling, ClaRa, Validation

\section{Introduction}

During normal operation of a power plant different chemical reactions lead to solid particles that are carried by the flue gas through the entire boiler. The amount and the composition of these particles mainly depend on two parameters. The first is the kind of fuel that is burned in the furnace. Using hard coal for example will lead to much less produced solid particles compared to burning waste and biomass as a substitute fuel. Secondly the arrangement and type of the burners influences the formation of the flame and thus influences the homogeneity of heat release and flame temperatures which might result in particle formation.

Parts of the produced amount of soot are taken up by the heat exchangers that are passed by the flue gas. This mechanism is called fouling. As written in (Effenberger, 2000) there are different impacts on the furnace. The rate of heat transfer of the tube bundles decreases which affects the temperature field such that it increases towards the end of the boiler. Furthermore the reduction of the flue gas cross section leads to higher flue gas velocities. Overall the plant efficiency decreases with rising fouling of the heat exchange surfaces because of a higher flue gas pressure drop over the boiler and decreasing steam temperatures.

Due to this facts, the aim is to have a minimum fouling. Since frequent shut-downs of the entire plant to clean the heat exchangers are not desired, so called soot blowers are used to blow the attached particles from the heat exchangers. To avoid a cool down of the outer layer of the heat exchangers, superheated steam is used for this purpose.

\section{Informative Background}

This study has been carried out under the programme "THERRI" (THermisches ERmüdungsRIsswachstum thermal fatigue crack growth) that is funded by the German Federal Ministry for Economic Affairs and Energy. The aim of this project is the development of a method and guideline for the fracture-mechanical assessment of thick-walled components in fossil-fueled power plants. The Chair of Technical Thermodynamics Rostock develops dynamic power plant models to provide thermodynamic boundary conditions, i.e. thermal and mechanical loads for subsequent fracture-mechanical tests and analyses. The dynamic model was developed within the software environment "Dymola" using the programming language "Modelica". The components used to build the model are largely from of the ClaRa library that is described in the following part.

\subsection{Used Library - ClaRa}

The ClaRa (Clausius-Rankine) is an open source library that has been developed under the programme "Dyncap" which was as well as "THERRI" funded by the German 
Federal Ministry for Economic Affairs and Energy. It is written in Modelica modelling language. It allows the user to model highly detailed complete power plants with a strong focus on their dynamic behaviour (ClaRa, 2015; Brunnemann et al., 2012).

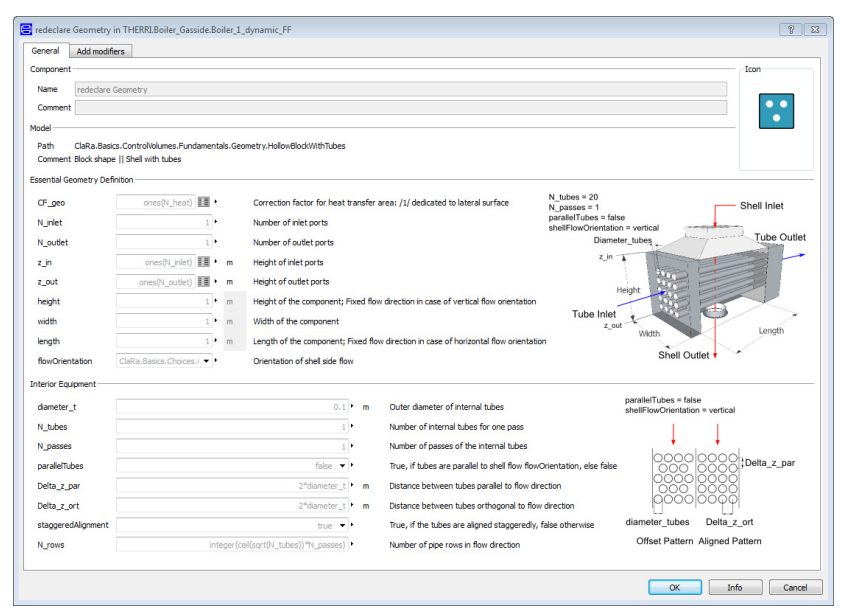

Figure 1. Example of Parameter GUI in ClaRa Library (ClaRa, 2015)

The library is divided into the following subpackages:

Table 1. Overview of the ClaRa library structure

\section{i. UsersGuide}

Examples

a Basics

E Components

․ SubSystems

E. Visualisation

[ StaticCycles modelling concept, contacts, license

introducing examples

base models and

informational structure

component models, see

Table 2

definition of subsystems for large projects

tools for visualisation, e.g. time plots

static models for calculation of initial values of upstream components for varying design points. The same procedure can be used to calculate nominal values for the main cycle.

The usable components are divided into base types containing various models at different levels of detail. Thus the user is able to create models that are as detailed as necessary and as simple as possible. Table 2 gives an overview of the implemented component classes. All

Table 2. Overview of the ClaRa subpackage Components
BoundaryConditions

ㅁ. TurboMachines

HeatExchangers

Mills

VolumesValvesFittings

- MechanicalSeparation

Eurnace

Electrical

Sensors

Control

Edapters

FlueGasCleaning sinks and sources for water, steam and gas

fans, compressors pumps and turbines

different heat exchanger types

mills for preparation of solid fuels

volumes, valves and fittings for water, steam and gas

gravitational phase separation, storage

base models for setting up entire boilers

electrical machinery

sensors for pressure, mass flow, temperature, etc.

base models for control purposes

adapters for related

Modelica libraries

denitrification, desulfurization and dedusting of flue-gas
The ClaRa is delivered with a package containing a set of stationary models which can be used to create a simplified, static and parameter-based mimic of the dynamic cycle. The result, a load depending set of parameters for mass flow, pressure and enthalpy for the complete cycle, can be used as initial guess values when linked to the respective parameters of the dynamic cycle. This allows the user to give flexible and consistent initial values at all dynamic components considering system topology and the possibility to use a cascaded initialisation with values component models are validated based on literature data and/or measurement data of existing components.

The ClaRa comes with a non-profit version of the TILMedia. Three different media types needed for the simulation of coal fired power plants are available. For pure mediums like water/steam there are table based and spline interpolated data available which are very encouraging concerning simulation speed and simulation stability, see (Schulze, 2013). The flue gas is described by a gas-vapour mixture similar to humid air. A mixture of 
real fluids for application in $\mathrm{CO}_{2}$-separation processes is supported too. For pressure loss and heat transfer the FluidDissipation library is used. For special purposes additional heat transfer correlations and radiation models can be used inside the combustion chamber.

For heat transfer the Modelica.Thermal connectors are used. The fluid connectors are in principle the same as the Modelica.Fluid connectors (despite the use of Temperature instead of enthalpy for gas flows) but they are using external substance properties and media types of the TILMedia ClaRa library making an own connector necessary. One main reason for the use of TILMedia $\mathrm{ClaRa}$ is that it is capable of calculating single and multicomponent vapor liquid equilibrium substances. The use of an external library comes with the advantage of a faster translation process and independence from the Modelica.Media being able to administrate, adapt and expand the needed substance properties according to the focus and requirements of the ClaRa.

\subsection{Reference Power Plant}

The investigated power plant is a hard-coal fired supercritical mono-block power plant Rostock. It is shown in Figure 2. The produced electric output is about $550 \mathrm{MW}$

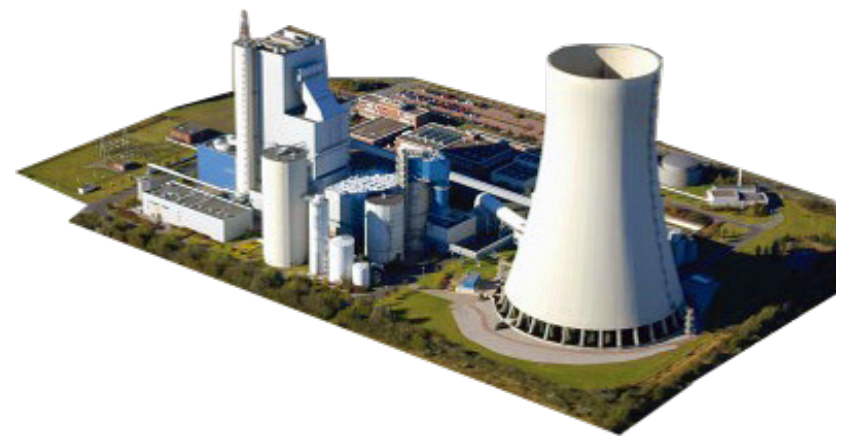

Figure 2. Investigated reference power plant Rostock

with an overall efficiency of approximately $43.2 \%$ at full load. The maximum thermal output of the tower arranged forced circulation boiler is $1370 \mathrm{MW}$. At full load the plant operates with $417 \mathrm{~kg} / \mathrm{s}$ feed water mass flow and a live steam pressure of $262 \mathrm{bar}$ at $545^{\circ} \mathrm{C}$. After depressurizing in the high-pressure turbine the steam is reheated to $562^{\circ} \mathrm{C}$. In order to increase the fuel utilization ratio the plant is designed to decouple a maximum of $300 \mathrm{MW}_{\text {th }}$ in combined heat and power cycle mode. Through this the utilization ratio can be risen up to $62 \%$. A simplified schematic diagram is shown in Figure 3 in order to avoid an explanation of the entire layout of the plant.

\section{Reduced Dynamic Model}

There are two reasons in dynamic modelling why for detailed investigation on particular parts it is very useful to cut out the most interesting part of the model and represent the left parts by boundary conditions. Firstly the duration of a simulation is heavily dependent on the deposited model size. Therefore a reduced model gives the ability to run the simulation more often e.g. for testing different sets of parameters. Secondly one get rid of the influences of uncertainties and assumptions made in the modelling of other devices and thus can compare different model results separately. For these reasons the complete plant has been reduced to the detailed boiler model that is described below. The model can be divided into 3 different parts, namely the gas side, water side and coal mill and combustion air section. The last part will not be treated in this paper, since its influence is not necessary for the investigations that will me made.

\subsection{Gas Side}

The gas side (see Figure 4a), which is responsible for modelling the heat release of the burned fuel, the transport of the flue gas through the entire boiler and the heat transfer via convection and radiation, is basically consisting the following submodels:

- Hopper and 4 Burner levels with coal dust inlet and an ideal combustion approach

- 2 Flamerooms with a port for tertiary air input

- 4 Superheater levels containing tube bundles and carrier tubes

- 2 Reheater levels containing tube bundles and carrier tubes

\section{- Economizer with finned tubes and carrier tubes}

For each of these submodels the exact geometries of the surrounding walls and the tubes are implemented as well as the combustion formulas and different heat transfer correlations. The submodels are connected to their corresponding neighbours through flue gas and heat transfer ports. The latter ones are used to model the radiation between the different boiler levels. Besides that, each submodel has one heat transfer interface to model the heat transfer to the surrounding wall. Additionally the superheater, reheater and economizer submodels contain one heat port defining the interaction with the tube bundles and another one describing the heating of the carrier tubes.

As already mentioned, the regarded heat transfer mechanisms are convection and radiation. For the radiation part the formula to calculate the heat flow is based on the Stefan-Boltzmann law of radiation. In accordance with (VDI, 2006) it can be calculated according to equation (1),

$$
\dot{Q}_{\mathrm{rad}}=A_{\mathrm{eff}} \sigma \frac{\varepsilon_{\mathrm{W}}}{\alpha_{\mathrm{G}}+\varepsilon_{\mathrm{W}}-\alpha_{\mathrm{G}} \varepsilon_{\mathrm{W}}}\left(\alpha_{\mathrm{G}} T_{\mathrm{W}}^{4}-\varepsilon_{\mathrm{G}} T_{\mathrm{G}}^{4}\right)
$$




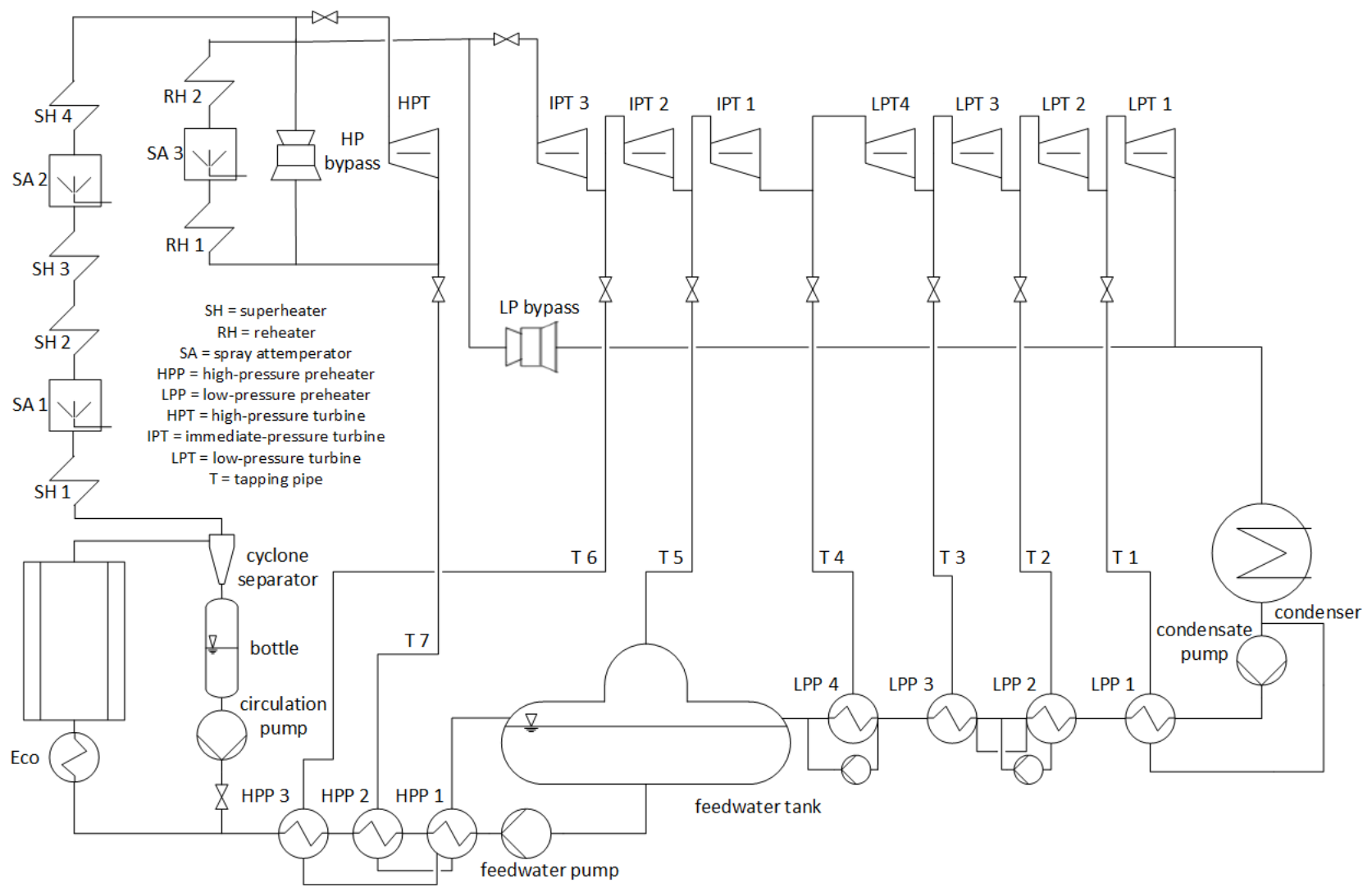

Figure 3. Schematic plot of the simplified water-steam cycle

where the emission and absorption coefficients of gas $\left(\varepsilon_{\mathrm{G}}, \alpha_{\mathrm{G}}\right)$ and the emission coefficient of the wall $\left(\varepsilon_{\mathrm{W}}\right)$ are approximated using the partial pressures of $p_{\mathrm{CO}_{2}}$ and $p_{\mathrm{H}_{2} \mathrm{O}}$ and the equivalent thickness $s_{\mathrm{gl}}$ as well as the ash and coke load of the flue gas. $T_{\mathrm{G}}$ and $T_{\mathrm{W}}$ are the temperatures of the gas and the surrounding wall. $\sigma$ stands for the Stefan-Boltzmann-Constant and the effective heat transfer area $A_{\text {eff }}$ is defined as the actual heat transfer area multiplied by a fouling factor $F_{\mathrm{F}}$ which is used as the elementary connection between the physical and the developed mathematical model. Its behaviour will be further discussed in chapter 5 .

The convective heat transfer is based on Newton's law with the same convention for $A_{\text {eff }}$ and the Temperatures of the wall and the gas, $T_{\mathrm{w}}$ and $T_{\mathrm{g}}$,

$$
\dot{Q}_{\mathrm{conv}}=A_{\mathrm{eff}} \alpha\left(T_{\mathrm{w}}-T_{\mathrm{g}}\right) .
$$

The heat transfer coefficient $\alpha$ is defined as

$$
\alpha=\frac{N u \lambda}{L}
$$

where $L$ denotes the characteristic length and $N u$ is a function of $\operatorname{Re}$ and $\operatorname{Pr}$ for laminar and turbulent flow.

\subsection{Water / Solid Side}

This submodel basically consists of pipe, valve and wall models. Each pipe has its assigned wall parametrized with the necessary information for heat transfer and thermal inertia like inner and outer diameters $\left(r_{\mathrm{i}}, r_{\mathrm{o}}\right)$, material properties (e.g. the coefficient of thermal conduction $\lambda$ ) and the total heat transfer surface. The conductive heat transfer through the walls is calculated based on (O'Kelly, 2012) with the Fourier law of heat conduction,

$$
\dot{Q}=-2 \pi \lambda l \frac{\Delta T}{\ln \frac{r_{\mathrm{o}}}{r_{\mathrm{i}}}}=\frac{\lambda A \Delta T}{r_{\mathrm{o}}-r_{\mathrm{i}}}
$$

wherein $\Delta T$ denotes the temperature difference between the inner and the outer phase of the pipe wall and the effective heat conduction surface $A$ follows equation (5).

$$
A=2 \pi l \frac{r_{\mathrm{o}}-r_{\mathrm{i}}}{\ln \frac{r_{\mathrm{O}}}{r_{\mathrm{i}}}}
$$

The pressure drop of the water/steam in the pipes is calculated with a nominal value $\Delta p_{\text {nom }}$ and a linear mass flow dependency,

$$
p_{\text {in }}-p_{\text {out }}=\Delta p_{\text {nom }} \frac{\dot{m}}{\dot{m}_{\text {nom }}} .
$$

The convective heat transfer between the inner phase of the pipe and the fluid inside is assumed as well to be linear mass flow dependent with a nominal heat transfer coefficient. The different pipe diameters and geometries of the evaporator are regarded through different models for the hopper, burner, flame room and superheater 


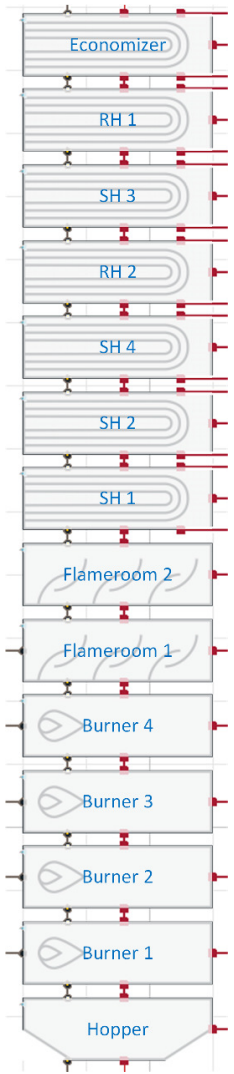

(a) Gas Side

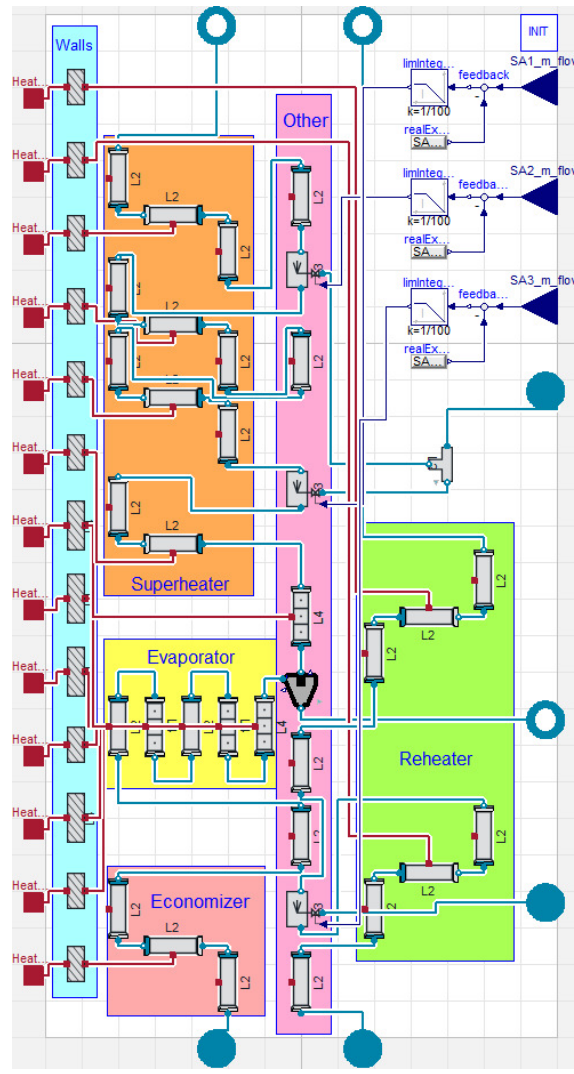

(b) Water Side
Figure 4. Gasside and Waterside parts of the developed boiler model

levels. Implementing this the relationship between the pipe lengths, the according heat transfer surfaces and the prevalent flue gas temperatures are taken into account. A schematic overview of this discretisation is given in Figure $4 \mathrm{~b}$. The arrowed connection lines are points where boundary conditions are applied. For controlling the steam temperatures in different levels, preheated water is sprayed into the steam pipe. The corresponding spray attemperators ("SA") are located between the superheaters $1 \& 2,3 \& 4$ as well as the reheaters $1 \& 2$. In the developed model the volume of main steam and spray is designed ideally stirred.

\section{Analysis of Soot Blowing Influence}

The soot blowing has complex physical effects on the heat transfer at the gas side part of the boiler. The attached constituents are partially blown away and chemical reactions may occur. For the applied 0D-/1D approach it appears to be sophisticated to design the physical background to model the exact behaviour. Additionally to the physical mechanisms the unit control is influenced as well. All these facts lead to the approach for this study, which is a hybrid method combining mathematical and physical modelling approaches.

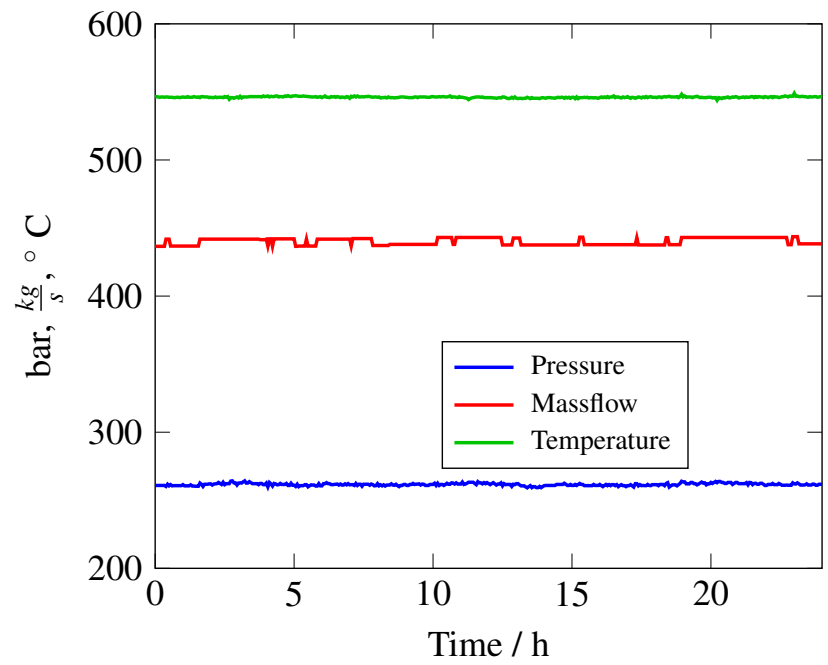

Figure 5. Live steam parameter of investigated load scenario

To identify the transfer functions, a real scenario of one day from the reference power plant (see Chapter 2.2) with steady load is used as database. This decision has been made due to the advantage, that in case of no load changes the soot blowing effects can be investigated separately without regarding other influences. The significant live steam parameters, as they can be seen in Figure 5, are nearly constant. Since the steam parameters do not change significantly the steam mass flowing through the whole boiler can be seen as stationary. This allows in further calculations to use the temperature difference between the inlet and the outlet of a superheater as an indicator for the heat flow.

In this study the focus of investigation lies on the first and fourth superheater. Nevertheless the method can be used to determine the soot blowing influence of further heat exchangers in the boiler. In Figure 6 the direct influence of soot blowing on one of the corresponding superheaters is shown. During the process the reached temperature difference rises and afterwards it decreases slowly until a certain normal level of $\Delta T \approx 12 \mathrm{~K}$ in this example.

In addition to that the investigated process also affects the heat transfer of other heat exchanger areas. In this study the coherences between the heat transfer of superheater 1 and 4 are used as an exemplary case. Therefore Figure 7 shows the temperature difference of superheater 4 for the same scenario. In this plot, additionally to the former, the soot blowing intervals of some other heating surfaces are illustrated. It appears that the temperature difference decreases when blowing in superheater 1 level which is located approximately $4.5 \mathrm{~m}$ below the superheater 4 . After these events it takes several hours to reach the previous amount of temperature difference or even a new operating point.

Another influence that can be seen is the soot blowing of the superheater 2 level that is located directly below the superheater 4. Having a look on Figure 7 it seems that the lance of superheater 2 also detaches some soot 


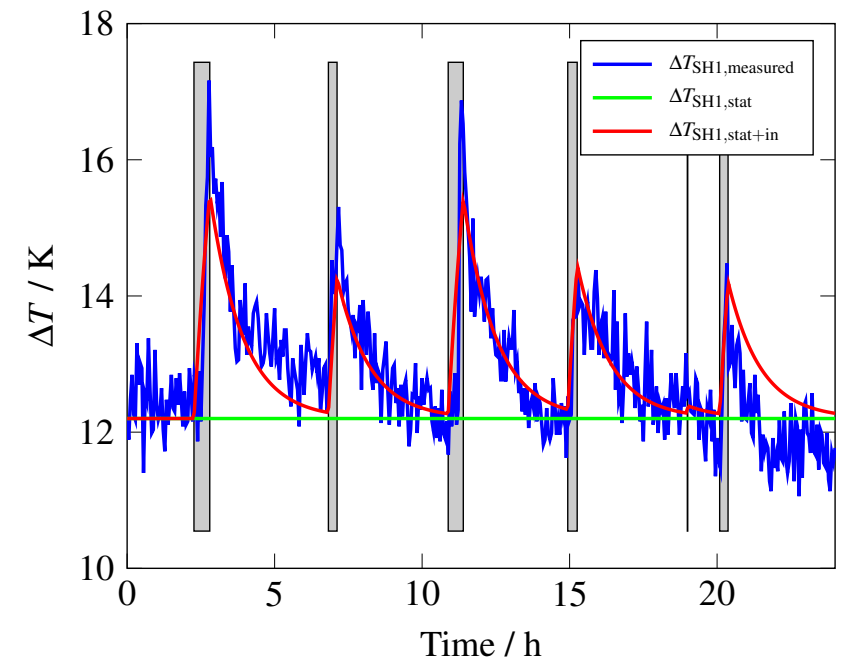

Figure 6. Steam temperature difference of superheater 1 with soot blowing interval (grey)

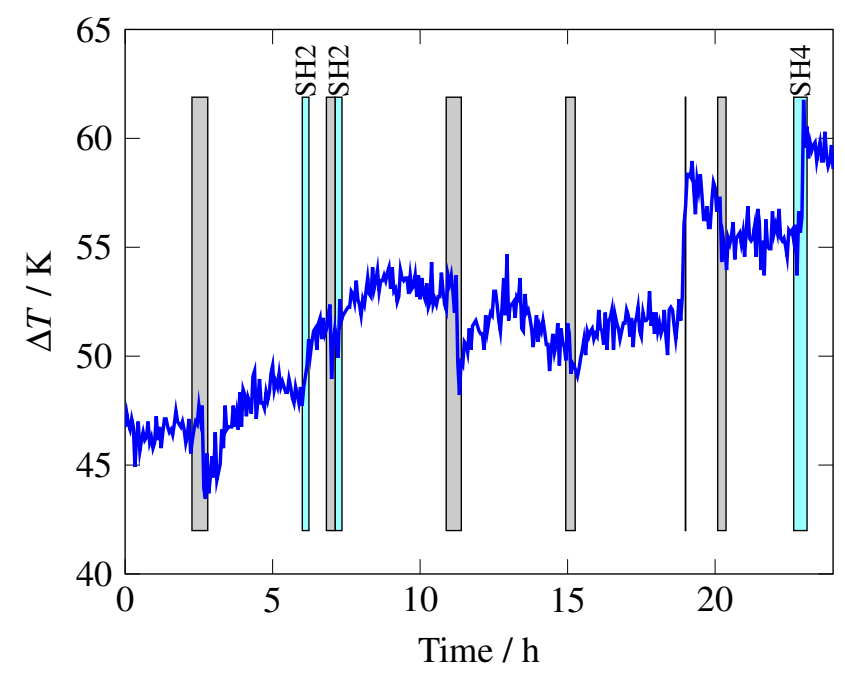

Figure 7. Steam temperature difference of superheater 4 with soot blowing interval of superheater 1 (grey) and superheater 2 and 4 (light blue)

and particles from superheater 4 .

The steep ramp at $18 \mathrm{~h}$ is caused by a spray attemperator event and thus remains unregarded in this study.

\section{Model Design}

As already mentioned an exact physical approach is too complex to model in 0D/1D environments. Perhaps it would be worth to examine the behaviour using a detailed 3D-CFD method which is not part of this study.

The strategy of this study is to use a condensed mathematical model based on simple transfer functions. As described through the equations (1) and (2) in chapter 3.1 the heat flow of a superheater can be adjusted by the effective heat transfer area or more specifically the fouling factor $F_{\mathrm{F}}$. This context is used to affect the different tube bundles due to the soot blowing. To increase the overall heat transfer ability of a superheater, one raise the fouling factor of the according submodel at the gas side model and vice versa. Therefore the ClaRa implementation of $F_{\mathrm{F}}$ as a fixed parameter has been changed to a variable real value that is modifiable from outside the specific submodel. The method to identify the different values of the fouling factors is described in (Gierow et al., 2015) and thus is regarded as known for this study.

As an simplification for the modelling of the soot blowing influence, $F_{\mathrm{F}}$ is divided into two parts, $F_{\mathrm{F}}=$ $F_{\text {stat }}+F_{\text {in }}$. Herein $F_{\text {stat }}$ describes the stationary or offset part of the fouling factor at the current status. The corresponding temperature difference $\Delta T_{\text {stat }}$ is marked as a green line in Figure 6. The soot blowing is assumed to have no influence on this part. The second term is denoted as an influence factor, changing its value due to soot blowing events. Through this assumption it is possible to model and modify just the transient part of the fouling factor. In case of a stationary operation with no soot blowing it will remain at zero. This gives the huge advantage of the possibility to connect it to a binary signal indicating the on/off-state of the soot blowers. The entire mathematical model for this approach is described in the following.

As it may be seen by the red line in Figure 6, the transient temperature response is assumed to be proportional with a first order delay, also known as a $\mathrm{PT}_{1}$-element. Since all soot blowers in the boiler have to be taken into account, the complete system is defined with multiple inputs $\underline{u}$ and outputs $\underline{x}$ (MIMO). For $m$ heat exchangers and $n$ soot blowers the system is in the state-space representation form

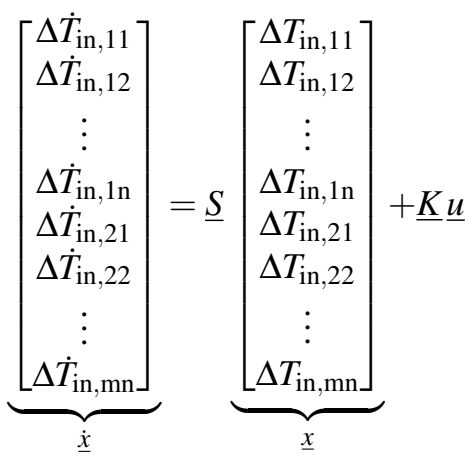

where $\underline{u}$ means a column vector of states of the investigated soot blowers. Active blowers are treated as $u_{i}=1$ and inactive ones as $u_{i}=0$. The state and input matrices are built as follows,

$$
\begin{aligned}
& \underline{S}=\operatorname{diag}\left(S_{11}, S_{12}, \ldots, S_{1 n}, S_{21}, S_{22}, \ldots, S_{m n}\right) \\
& \underline{K}=\left[\begin{array}{c}
\operatorname{diag}\left(K_{11}, K_{12}, \ldots, K_{1 n}\right) \\
\operatorname{diag}\left(K_{21}, K_{22}, \ldots, K_{2 n}\right) \\
\vdots \\
\operatorname{diag}\left(K_{m 1}, K_{m 2}, \ldots, K_{m n}\right)
\end{array}\right]
\end{aligned}
$$


The entries of the state matrix $S$ contain the time constants of the delay part of the $\mathrm{PT}_{1}$ element in the form $S_{i j}=-\tau_{i j}^{-1}$. Since the fouling factors itself have no physical influence on each other, the non-diagonal entries of the matrix can be treated as zeros, $S_{i j}=0$ for $i \neq j$. The input matrix $\underline{K}$ represents the proportional gains between the soot blowers and the heat exchanger fouling factors. Since, considering the equations (1) and (2), the fouling factor influences the temperature difference in the first approximation linearly, the stationary temperature differences and fouling factors can be used to convert the state vector $\underline{x}$ to the desired values of $\underline{F}_{\text {in }}$ by multiplication with the output matrix $\underline{C}$,

$$
\left[\begin{array}{c}
F_{\mathrm{in}, 1} \\
F_{\mathrm{in}, 2} \\
\vdots \\
F_{\mathrm{in}, \mathrm{m}}
\end{array}\right]=\underbrace{\operatorname{diag}\left(\underline{c}_{1}, \underline{c}_{2}, \ldots, \underline{c}_{m}\right)}_{\underline{C}} \underline{x}
$$

with

$$
\underline{c}_{i}=\underbrace{\left[\begin{array}{cccc}
c_{i} & c_{i} & \ldots & c_{i}
\end{array}\right]}_{\mathrm{n}-\mathrm{times}}
$$

After the identification process the whole mathematical model of the soot blowing influence is implemented into the physical model of the gas side of the boiler as shown in Figure 8.

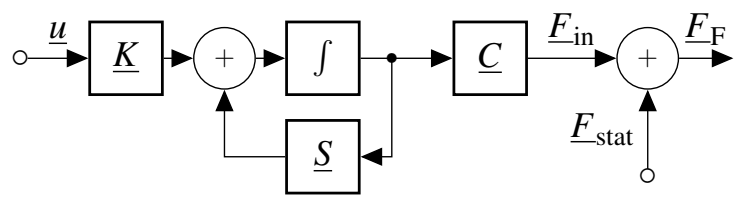

Figure 8. Block diagram of implementation in Dymola

\section{Results and Validation}

To avoid oversized matrices, the mathematical model is shrinked to the heat exchange of the superheaters 1 and 4 and the soot blowing in superheater 1 and 2 as already mentioned in chapter 4 . Unfortunately the spray attemperator event at approx. 18h cannot be reproduced with the current status of the dynamic boiler model. For this reason the investigated time span for identification and validation is reduced by seven hours. During this time the soot blower of superheater 4 is not active and thus will be neglected from now on. Since the soot blower of the superheater 2 is located above the superheater 1 , there is no influence between. For this reason the appropriate rows and columns in the matrices are omitted. This simplifies the model to the following form:

$$
\begin{aligned}
& \underline{\dot{x}}=-\left[\begin{array}{ccc}
\tau_{\mathrm{SH} 1,1}^{-1} & 0 & 0 \\
0 & \tau_{\mathrm{SH} 4,1}^{-1} & 0 \\
0 & 0 & \tau_{\mathrm{SH} 4,2}^{-1}
\end{array}\right] \underbrace{\left[\begin{array}{l}
\Delta T_{\mathrm{in}, \mathrm{SH} 1,1} \\
\Delta T_{\mathrm{in}, \mathrm{SH} 4,1} \\
\Delta T_{\mathrm{in}, \mathrm{SH} 4,2}
\end{array}\right]}_{\underline{x}}+ \\
& +\left[\begin{array}{cc}
K_{\mathrm{SH} 1,1} & 0 \\
K_{\mathrm{SH} 4,1} & 0 \\
0 & K_{\mathrm{SH} 4,2}
\end{array}\right]\left[\begin{array}{l}
u_{\mathrm{SH} 1} \\
u_{\mathrm{SH} 2}
\end{array}\right] \\
& {\left[\begin{array}{c}
F_{\text {in }, \mathrm{SH} 1} \\
F_{\text {in }, \mathrm{SH} 4}
\end{array}\right]=\left[\begin{array}{ccc}
\frac{F_{\text {stat }, \mathrm{SH} 1}}{\Delta T_{\text {stat }, \mathrm{HH} 1}} & 0 & 0 \\
0 & \frac{F_{\text {stat }, \mathrm{SH} 4}}{\Delta T_{\text {stat }, \mathrm{SH} 4}} & \frac{F_{\text {stat }, \mathrm{SH} 4}}{\Delta T_{\text {stat }, \mathrm{SH} 4}}
\end{array}\right] \underline{x}}
\end{aligned}
$$

The identification problem thus is reduced to 6 independent variables. For handling this problem it is split into two sub-problems and then solved with the system identification toolbox of MATLAB ${ }^{\circledR}$.

Table 3. Identified parameters

\begin{tabular}{lll}
\hline Variable & SH1 & SH4 \\
\hline$\Delta T_{\text {stat }}[\mathrm{K}]$ & 12.2 & 50.2 \\
$F_{\text {stat }}$ & 0.64 & 0.61 \\
$c=\frac{F_{\text {stat }}}{\Delta T_{\text {stat }}}\left[\frac{1}{\mathrm{~K}}\right]$ & 0.05246 & 0.01216 \\
$\tau_{1}[\mathrm{~s}]$ & 3992 & 5437 \\
$\tau_{2}[\mathrm{~s}]$ & - & $4.5 \mathrm{e} 9$ \\
$K_{1}$ & $2.154 \mathrm{e}-3$ & $-2.364 \mathrm{e}-3$ \\
$K_{2}$ & - & $4.22 \mathrm{e}-3$ \\
\hline
\end{tabular}

For the investigated scenario the parameters in Table 3 have been identified. There are different aspects that can be deduced from some parameters. For instance the soot blowing at the superheater 1 has a negative gain for the temperature difference of superheater 4 and thus will reduce the temperature difference over this tube bank. Another point is the high delay time $\tau_{2}$ of superheater 4 . It appears that it is so high, that the delay part is negligible. This means the influence has only an integrative character.

Figure 9 and Figure 10 show the results of the already mentioned scenario simulated using the highly detailed boiler model described in chapter 3 with an implemented soot blowing model containing the parameters shown in Table 3. Both temperature trajectories can be reproduced using the developed model approach. The deviation after $12 \mathrm{~h}$ in Figure 10 is reasoned by the rough discretisation of the measurement data which is used for the boundary conditions during the simulation. Based on the overall results the applied approach assuming a first-order behaviour appears to be sufficient. 


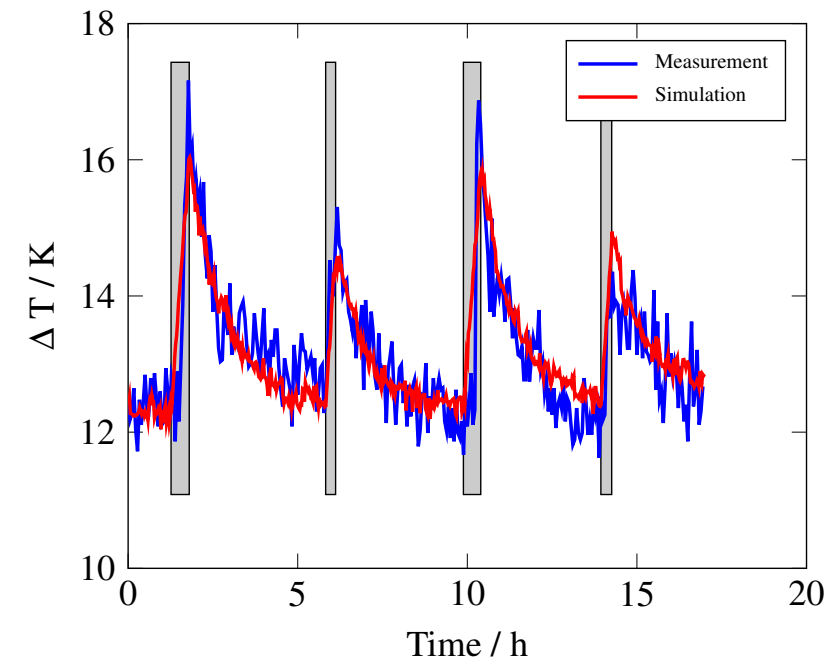

Figure 9. Comparison of simulated and measured steam temperature difference of superheater 1 with the corresponding soot blowing interval (grey)

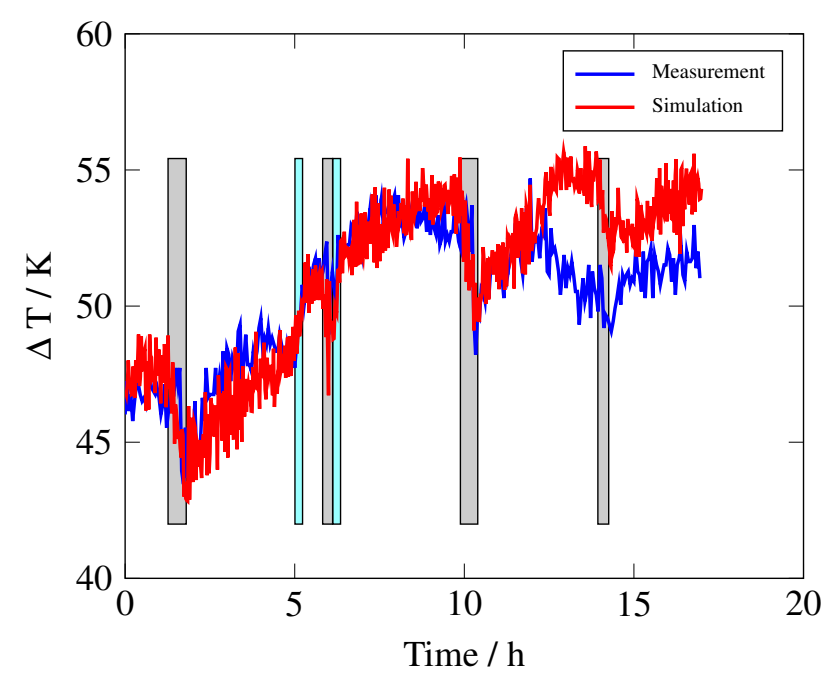

Figure 10. Comparison of simulated and measured steam temperature difference of superheater 4 with soot blowing interval of superheater 1 (grey) and superheater 2 (light blue)

\section{Summary and Outlook}

In this paper an innovative and in terms of computational costs resource-efficient algorithm to include the soot blowing influence into a dynamic power plant has been presented. The model allows to investigate both, the direct influence of soot blowing on the appropriate superheater and how it affects the superheaters that coming afterwards in flue gas direction. For a steady load scenario the accuracy and validity of the method has been shown.

In the next stages further studies will follow concerning load changes and scenarios with different stationary fouling factors. Furthermore this study could be compared to a more physical approach considering chemical reactions and the enthalpy flow into the flue gas. In case of completely validated models, control optimisations could be possible, e.g. to avoid any influence of soot blowing on the spray injection dynamics.

\section{Acknowledgement}

The authors would like to thank the German Federal Ministry for Economic Affairs and Energy for funding the project. Furthermore we would like to thank all the partners in the project, especially the people working at the reference power plant for supporting us incessantly and giving us all the necessary information and data for the dynamic modelling. In addition we would like to thank the development team of the ClaRa and TILMedia ClaRa libraries from XRG Simulation GmbH and TLKThermo GmbH for their competent and fast support.

\section{References}

Johannes Brunnemann, Friedrich Gottelt, Kai Wellner, Ala Renz, André Thüring, Volker Roeder, Christoph Hasenbein, Christian Schulze, Gerhard Schmitz, and Jörg Eiden. Status of ClaRaCCS: Modelling and simulation of coal-fired power plants with CO2 capture. In Proceedings of the 9th International Modelica Conference, 2012.

ClaRa. dyncap I ClaRa - Simulation von Clausius-RankineKreisläufen, May 2015. URL www. claralib.com.

Helmut Effenberger. Dampferzeugung. Springer, 2000. ISBN 3-540-64175-0.

Conrad Gierow, Moritz Hübel, Jürgen Nocke, and Egon Hassel. Vergleich von Algorithmen zur Identifikation der Heizflächenverschmutzung. In In Print: Kraftwerkstechnisches Kolloquium, Dresden, 2015.

P. O'Kelly. Computer Simulation of Thermal Plant Operations. Springer New York, 2012. ISBN 978-1-461-44256-1.

Christian Schulze. Numerisch effizientes Modellieren von thermodynamischen Systemen. In 16. ITI Symposium, Dresden, 2013.

VDI. VDI-Wärmeatlas. Springer, Berlin, Heidelberg, 10th edition, 2006. ISBN 978-3-540-25503-1. 